\title{
STRATEGI PENGEMBANGAN USAHA EMPING TIKE PADA INDUSTRI RUMAH TANGGA
}

\author{
Kerin Alfebry $^{1}$, Juri Juswadi ${ }^{2}$, Yudhi Mahmud ${ }^{3}$ \\ 1,2,3 Program Studi Agribisnis, Fakultas Pertanian, Universitas Wiralodra \\ E-mail: kerinkerin007@gmail.com¹, yuswadi_yuri@yahoo.co.id ${ }^{2}$,yudhi8527@gmail.com
}

\begin{abstract}
ABSTRAK
Penelitian ini bertujuan untuk 1) Mengetahui kekuatan, kelemahan, peluang, dan ancaman yang dihadapi dalam usaha emping tike di Desa Jumbleng Kecamatan Losarang Kabupaten Indramayu, 2) Menetapkan strategi pengembangan Usaha emping tike berdasarkan analisis SWOT.Penelitian ini dilakukan di Desa Jumbleng Kecamatan Losarang Kabupaten Indramayu. Pengambilan sampel dengan menggunakan cara Simple Random Sampling adalah metode dengan jumlah responden sebanyak 12 pengusaha. Metode penelitian yang digunakan dengan survei, desain penelitian survei deskriftif. Jenis data yang digunakan yaitu data primer dan data sekunder. Data primer diperoleh dari wawancara melalui kuesioner.Hasil penelitian yang diperoleh yaitu Kekuatan home industry emping tike di Desa Jumbleng. Dipilih 3 strategi yang tepat untuk pengembangan yaitu : Strategi I : Memanfaatkan teknologi dan informasi untuk meningkatkan peminat dan memperluas areal promosi usaha emping tike. ( Strategi Integrasi ke depan, integrasi kebelakang, penetrasi pasar).Usaha emping tike di Desa Jumbleng Kecamatan Losarang Kabupaten Indramayu berada pada kuadran II dengan jumlah skror IFE 3,040 dan total skor EFE 2,764 yang artinya tumbuh pertahankan atau pelihara. Memanfaatkan teknologi dan informasi untuk meningkatkan peminat dan memperluas areal promosi usaha emping tike. Dengan jumlah skor TAS 6,435.
\end{abstract}

Kata kunci : Emping tike, , Industri rumah tangga, Strategi pengembangan

\section{PENDAHULUAN}

Agribisnis adalah berasal dari kata agri dan bisnis. Agri berasal dari bahasa inggris, agricultural (pertanian). Bisnis berarti usaha komersial dalam dunia perdagangan. (Soekartawi, 2001)

Agroindustri adalah kegiatan yang memanfaatkan hasil pertanian sebagai bahan baku, merancang dan menyediakan peralatan serta jasa untuk kegiatan tersebut. Secara eksplisit agroindustri adalah perusahaan yang memproses bahan nabati (yang berasal dari tanaman) atau hewani (yang dihasilkan oleh hewan).

Proses yang digunakan mencakup pengubahan dan pengawetan melalui perlakuan fisik atau kimiawi,penyimpanan, pengemasan dan distribusi.Produk agroindustri ini dapat merupakan produk akhir yang siap dikonsumsi ngah atau perusahaan- perusahaan besar. Salah satu industri kecil yang ada di Kabupaten Indramayu adalah home industri emping tike yang merupakan produksi khas wilayah Indramayu. Home industri emping tike di Kabupaten Indramayu tersebar di dua kecamatan yaitu Kecamatan ataupun sebagai produk bahan baku industri lainnya. (Soekartawi, 2001)

Kabupaten Indramayu merupakan salah satu kabupaten di Provinsi Jawa Barat yang memiliki banyak industri kecil dan rumah tangga yang tersebar di setiap kecamatan bahkan desa. Home industri yang tergolong ke dalam industri kecil ini bersifat informal yang pengelolaannya dikelola oleh perseorangan atau pada ruang lingkup rumah tangga. Selain itu, dalam home industri pada umumnya hanya menggunakan satu atau dua rumah untuk proses produksi, administrasi dan pemasaran dilakukan secara bersamaan. Jika dilihat dari modal usaha yang dikeluarkan serta serapan tenaga kerja pastinya lebih sedikit dibandingkan dengan industri mene Karangampel dan Kecamatan Losarang.

Usaha emping tike di Desa Jumbleng ini sudah berlangsung selama 40 tahun lebih. Dalam perkembangannya usaha ini menghadapi kendala yaitu a) keterbatasan bahan baku umbi tike pada saat 
musim hujan, b)keterbatasan modal, c) belum terkondisikannya usaha industri setempat dikarenakan tidak adanya lembaga hukum seperti koperasi atau badan lainnya yang dapat mengatur kebijakan usaha setempat yang dapat menimbulkan persaingan usaha yang tidak sehat antar pengusaha dalam hal penentuan harga jual dan pendistribusian pasar. Pada saat ini industri emping tike masih memasarkan produksinya di wilayah Indramayu, namun pengusaha emping tike di Desa Jumbleng Kecamatan Losarang menyertakan label atau cap sebagai salah satu bentuk promosi dalam memperkenalkan produk tersebut. Menurut data Diskoperindag pada tahun 2014 jumlah pemilik usaha emping tike di Desa Jumbleng berjumlah 51 pengusaha. Selain di Desa Jumbleng Pengusaha emping tike juga terdapat di Desa Pangkalan Kecamatan Losarang. Tetapi setiap tahunnya keberadaan pengusaha keripik tike mengalami fluktuasi, dikarenakan bahan baku yang didapat musiman dan sulit didapat. Saat ini pengusaha emping tike di Desa Jumbleng berjumlah 22 orang. Seperti ditunukan dalam tabel 1.

Tabel 1. Daftar Sentra Industri Kecil dan Menengah Emping Tike pada Tahun 2017

\begin{tabular}{ccccr}
\hline No. & Desa & \multicolumn{2}{c}{ Kecamatan } & \multicolumn{2}{c}{ Unit } \\
& & & Usaha \\
\hline 1. & & Jumbleng & Losarang & 22 \\
2. & & Pangkalan & Losarang & 6 \\
\hline & Total & & & 28 \\
\hline
\end{tabular}

Sumber : Dinas Koperasi, UKM, Perindustrian dan Perdagangan Kabupaten Indramayu 2017

\section{METODE PENELITIAN}

\section{Objek Penelitian}

Objek penelitian ini adalah kelompok industri rumah tangga yang memproduksi emping tike di Desa Jumbleng Kecamatan Losarang Kabupaten Indramayu. Kegiatan pengambilan data dilakukan sejak Oktober 2018 hingga januari 2019.

\section{Metode Pengumpulan Data}

Metode yang digunakan dalam penelitian ini menggunakan metode survey. Desain penelitian yang digunakan adalah metode suvei deskriftif yang merupakan desain penelitian yang digunakan untuk mencari fakta dengan interpretasi yang tepat terhadap suatu objek, status kelompok manusia, suatu set kondisi, suatu sistem pemikiran dan suatu kelas tertentu. Usaha pengolahan data dibantu dengan analisis SWOT,Matriks EFE dan QSPM (Quantitative Strategik Planning Matriks) sehingga diperoleh strategi yang tepat.

Data yang digunakan dalam penelitian ini yaitu data primer adalah data yang diperoleh dari hasil suvei atau observasi secara langsung melalui pengisian kuesioner. Data sekunder adalah data yang diperoleh ini dari studi pustaka, internet, instansi terkait maupun literature lainnya yang menunjang dalam penelitian ini.

Metode Pengumpulan Sampel

Adapun rumus yang digunakan dalam pengambilan sampel ini yaitu dengan menggunakan rumus Slovin.

$$
\text { Rumus : } n=\frac{N}{1+N(e)^{2}}
$$

Keterangan :

$\mathrm{n}$ : Ukuran sampel / jumlah responden $\mathrm{N}$ : Ukuran populasi

$\mathrm{E}$ : Presentase kelonggaran ketelitian kesalahan pengambilan sampel yang masih bias ditolelir; $\mathrm{e}=0,2$ 
Dalam rumus Slovin ada ketentuan sebagai berikut :

Nilai e $=0,1(10 \%)$ untuk populasi dalam jumlah besar

Nilai e $=0,2(20 \%)$ untuk populasi dalam jumlah kecil

Jadi rentang sampel yang dapat diambil dari teknik Slovin adalah antara10-20\% dari populasi penelitian.

\section{HASIL DAN PEMBAHASAN}

\section{Faktor-Faktor SWOT}

Hasil dari data primer diperoleh faktor internal (kekuatan dan kelemahan) dan faktor eksternal (peluang dan ancaman) yang dimiliki dari usaha industri Emping Tike yang berada di Desa Jumbleng Kecamatan Losarang Kabupaten Indramayu rata-rata memiliki faktor internal dan faktor eksternal yang sama.

\section{Kekuatan (Strenght)}

1) Tingginya kemauan dan keuletan pemilik dalam mengelola usaha

2) Produknya banyak diminati

3) Tenaga kerja tersedia

4) Produk berkualitas dan memiliki izin

\section{Kelemahan (Weakness)}

1) Kurang adanya promosi produk

2) Masih menggunakan cara tradisional

3) Bahan baku relative sulit diperoleh

4) Tata kelola keuangan masih sederhana

\section{Peluang (Opportunity)}

1) Dukungan dari pemerintah daerah setempat

2) Tersedianya fasilitas teknologi dan informasi untuk memperluas areal promosi dan pemasaran yang lebih luas

3) Permintaan meningkat sangat pesat pada saat hari-hari besar keagamaan

4) Peluang Pasar Masih Terbuka

\section{Ancaman (Threats)}

1) Duplikasi produk oleh usaha lain

2) Ketidaktersediaan bahan baku karena kurang terjangkaunya ketersediaan bahan baku

3) Daya beli masyarakat rendah

4) Fluktuasi harga bahan baku 


\section{Matriks SWOT}

\section{Matriks Lingkungan Internal dan Eksternal}

Tabel 2. Matriks SWOT Usaha Emping Tike

Peluang (O)
Faktor Ekternal
1. Dukungan dari pemerintah
daerah setempat
2. Tersedianya fasilitas teknologi
dan un
informasi untuk
memperluas areal
promosi dan pemasaran
yang lebih luas
3. Permintaan tinggi pada
saat hari-hari perayaan
4. Peluang Pasar Masih
Terbuka

\section{Kekuatan (S)}

1. Tingginya kemauan dan keuletan pemilik dalam mengelola usaha

2. Produknya banyak diminati

3. Memanfaatkan warga sekitar sebagai karyawan

4. Produk berkualitas dan memiliki izin
Kelemahan (W)
1. Kurang adanya promosi
2. Menggunakan cara tradisional
3. Bahan baku relatif sulit diperoleh
4. Pembukuan masih sederhana

1. Memanfaatkan teknologi dan 1. Memanfaatkan dukungan informasi guna meningkatkan peminat dan memperluas areal promosi usaha emping tike. (S2, O2).

2. Memanfaatkan tenaga kerja yang ada di sekitar lingkungan usaha agar menyediakan lapangan pekerjaan dan menghasilkan produk yang berkualitas untuk meningkatkan permintaan, 2. Manfaatkan teknologi memperluas jangkauan pasar bagi untuk mempermudah usaha emping tike yang terus meningkat. $(\mathrm{S} 3,04)$ pemerintah untuk mempromosikan emping tike agar emping tike dapat menembus pasar dan banyak diminati oleh masyarakat. (W1,O2)

dalam proses pembuatan dan pengemasan emping tike. (W2,O2)

\section{Ancaman (T)}

1. Duplikasi produk oleh usaha lain

2. Ketidaktersediaan bahan baku karena kurang terjangkaunya ketersediaan bahan baku

3. Penurunan Daya Beli Konsumen

4. Fluktuasi harga bahan baku
1. Menciptakan inovasi pada emping tike 1. Melakukan promosi produk agar duplikasi produk oleh usaha lain tidak terjadi dan mampu bersaing dengan produk sejenis.(S4,T1)

2. Bekerjasama dengan pemasok bahan baku tike agar usaha berjalan secara kontinyu.(S1,T2)

3. Melakukan diversifikasi produk agar konsumen emping tike dapat memilih sesuai dengan keinginannya.(S4,T3) emping tike secara intensif dan efektif melalui media masa.(W1,T3)

2. Menambah tenaga kerja dibagian pemasaran untuk meningkatkan penjualan.(W2,T3) 


\section{Pembobotan Dan Matriks IFE}

Tabel 3. Penilaian Bobot Faktor Strategi Internal

\begin{tabular}{|c|c|c|c|c|c|c|c|c|c|c|}
\hline Faktor strategi Internal & A & B & $\mathrm{C}$ & $\mathrm{D}$ & E & $\mathrm{F}$ & $\mathrm{G}$ & $\mathrm{H}$ & Jumlah & $\begin{array}{c}\text { Bobot } \\
\text { (ai) }\end{array}$ \\
\hline \multicolumn{11}{|l|}{ Kekuatan (S) } \\
\hline $\begin{array}{l}\text { A. Tingginya kemauan } \\
\text { dan keuletan pemilik dalam mengelola } \\
\text { usaha }\end{array}$ & & 2 & 2 & 3 & 3 & 3 & 3 & 2 & 18 & 0,143 \\
\hline $\begin{array}{l}\text { B. Produk emping tike } \\
\text { banyak diminati }\end{array}$ & 2 & & 3 & 3 & 2 & 2 & 3 & 2 & 17 & 0,135 \\
\hline C. Tenaga kerja tersedia & 2 & 2 & . & 3 & 3 & 3 & 3 & 2 & 18 & 0,143 \\
\hline $\begin{array}{l}\text { D. Produk berkualitas } \\
\text { dan memiliki izin }\end{array}$ & 2 & 2 & 2 & & 3 & 3 & 3 & 3 & 18 & 0,143 \\
\hline \multicolumn{11}{|l|}{ Kelemahan (W) } \\
\hline $\begin{array}{l}\text { E. Kurang adanya } \\
\text { Promosi }\end{array}$ & 2 & 2 & 2 & 2 & & 2 & 2 & 2 & 14 & 0,111 \\
\hline $\begin{array}{l}\text { F. Menggunakan cara } \\
\text { Tradisional }\end{array}$ & 2 & 1 & 2 & 2 & 2 & & 2 & 2 & 13 & 0,103 \\
\hline $\begin{array}{l}\text { G. Bahan baku relative } \\
\text { Sulit }\end{array}$ & 2 & 2 & 2 & 2 & 2 & 2 & & 2 & 14 & 0,111 \\
\hline $\begin{array}{l}\text { H. Pembukuan masih } \\
\text { Sederhana }\end{array}$ & 2 & 2 & 2 & 2 & 2 & 2 & 2 & & 14 & 0,111 \\
\hline Total & & & & & & & & & 126 & $\mathbf{1 , 0 0 0}$ \\
\hline
\end{tabular}

\section{Penentuan Matriks IFE}

Berdasarkan analisis faktor internal yang meliputi kekuatan dan kelemahan disusun setelah dilakukan identifikasi terhadap faktor internal yang meliputi kekuatan dan kelemahan pada Usaha Emping Tike. Hasil matriks IFE dapat dilihat pada tabel 13. Total seluruh skor faktor strategis adalah 3,040. Nilai tersebut menunjukan bahwa Usaha Emping Tike di Desa Jumbleng Kecamatan Losarang Kabupaten Indramayu berada pada rata-rata dalam kekuatan internal keseluruhan. Nilai skor untuk kekuatan adalah sebesar 1,835 sedangkan nilai skor untuk kelemahan adalah 1,205. nilai akhir skor total kekuatan yang lebih besar dari pada kelemahannya menunjukan bahwa dalam menjalankan usaha, pengusaha emping tike di Desa Jumbleng mampu memanfaatkan kekuatan yang dimiliki dan mengatasi kelemahannya.

Tabel 4. Matriks IFE (Internal Factor Evaluation)

\begin{tabular}{|c|c|c|c|c|c|}
\hline Kekuatan (S) & $\begin{array}{l}\text { Bobot } \\
\text { (B) }\end{array}$ & $\begin{array}{l}\text { Rating } \\
\text { (R) }\end{array}$ & $\begin{array}{c}\text { Skor } \\
(\mathrm{BxR})\end{array}$ & Prioritas & \\
\hline $\begin{array}{l}\text { 1. Tingginya kemauan dan } \\
\text { keuletan pemilik dalam mengelola } \\
\text { usaha }\end{array}$ & 0.143 & 3 & 0,429 & & 4 \\
\hline 2. Produknya banyak diminati & 0.135 & 3 & 0,405 & & 3 \\
\hline 3. Tersedianya tenaga kerja & 0.143 & 4 & 0,572 & & 3 \\
\hline $\begin{array}{l}\text { 4. Produk berkualitas dan } \\
\text { memiliki izin }\end{array}$ & 0.143 & 3 & 0,429 & & 4 \\
\hline Jumlah & & 13 & 1,835 & & \\
\hline
\end{tabular}


Kelemahan (W)

\begin{tabular}{lllll}
\hline 5. Kurang adanya promosi & 0.111 & 3 & 0,333 & 3 \\
6. Menggunakan cara tradisional & 0.103 & 2 & 0,206 & 3 \\
7. Bahan baku relatif sulit & 0.111 & 3 & 0,333 & 3 \\
8. Pembukuan masih sederhana & 0.111 & 3 & 0,333 & 3 \\
\hline \multicolumn{1}{c}{ Jumlah } & & $\mathbf{1 1}$ & $\mathbf{1 , 2 0 5}$ & $\mathbf{3 , 0 4 0}$ \\
\hline \multicolumn{1}{c}{ Jumlah Total } & $\mathbf{2 4}$ & &
\end{tabular}

Berdasarkan tabel diatas matriks IFE, kekuatan yang dimiliki pengusaha emping tike di Desa Jumbleng terletak pada tenaga kerja yang banyak, untuk itu memanfaatkan tenaga kerja yang ada agar merubah perekonomian masyarakatnya menjadi lebih baik. Memiliki skor 0,572 .

\section{Pembobotan Dan Matriks EFE}

Tabel 5. Penilaian Bobot Faktor Strategi Eksternal

\begin{tabular}{|c|c|c|c|c|c|c|c|c|c|c|}
\hline Faktor strategi Internal & A & B & $\mathrm{C}$ & $\mathrm{D}$ & E & $\mathrm{F}$ & G & $\mathrm{H}$ & Jumlah & $\begin{array}{l}\text { Bobot } \\
\text { (ai) }\end{array}$ \\
\hline \multicolumn{11}{|l|}{ Peluang $(\mathrm{O})$} \\
\hline $\begin{array}{l}\text { A. Dukungan dari } \\
\text { pemerintah daerah setempat }\end{array}$ & & 2 & 2 & 2 & 2 & 2 & 2 & 2 & 14 & 0,124 \\
\hline \multicolumn{11}{|l|}{$\begin{array}{l}\text { B. Memanfaatkan teknologi dan } \\
\text { informasi untuk memperluas areal } \\
\text { promosi dan menembus pasar }\end{array}$} \\
\hline & 2 & & 3 & 2 & 2 & 2 & 2 & 2 & 15 & 0,133 \\
\hline $\begin{array}{l}\text { C. Permintaan meningkat sangat } \\
\text { pesat } \\
\text { pada saat hari-hari besar } \\
\text { keagamaan }\end{array}$ & 2 & 1 & & 2 & 2 & 2 & 2 & 3 & 14 & 0,124 \\
\hline $\begin{array}{l}\text { D. Peluang Pasar Masih } \\
\text { Terbuka }\end{array}$ & 2 & 2 & 2 & & 2 & 2 & 2 & 2 & 14 & 0,124 \\
\hline \multicolumn{11}{|l|}{ Ancaman $(\mathrm{T})$} \\
\hline $\begin{array}{l}\text { E. Duplikasi produk } \\
\text { oleh usaha lain }\end{array}$ & 2 & 2 & 2 & 2 & & 3 & 2 & 2 & 15 & 0,133 \\
\hline $\begin{array}{l}\text { F. Ketidaktersediaan } \\
\text { bahan baku karena } \\
\text { perubahan musim yang } \\
\text { signifikan }\end{array}$ & 2 & 2 & 2 & 2 & 2 & & 2 & 2 & 14 & 0,124 \\
\hline $\begin{array}{l}\text { G. Daya beli konsumen } \\
\text { Rendah }\end{array}$ & 2 & 2 & 2 & 2 & 2 & 2 & & 2 & 14 & 0,124 \\
\hline $\begin{array}{l}\text { H. Fluktuasi harga } \\
\text { bahan baku }\end{array}$ & 2 & 1 & 2 & 2 & 2 & 2 & 2 & & 13 & 0,115 \\
\hline Total & & & & & & & & & 113 & 1,000 \\
\hline
\end{tabular}




\section{Penentuan Matriks EFE}

Matriks EFE disusun setelah dilakukan identifikasi terhadap faktor eksternal yang meliputi peluang dan ancaman pada usaha emping tike di Desa Jumbleng Kecamatan Losarang Kabupaten Indramayu. Hasil matriks EFE dapat dilihat pada tabel 15. Total skor faktor strategis ekternal adalah 2,764. nilai tersebut menunjukan bahwa usaha emping tike di Desa Jumbleng Kecamatan Losarang Kebupaten Indramayu berada pada rata-rata dalam kekuatan internal secara keseluruhan, adapun skor untuk peluang adalah 1,515 sedangkan skor untuk ancaman adalah 1,249. nilai akhir skor total peluang lebih besar dari pada ancamannya menunjukan bahwa dalam menjalankan usaha emping tike ini, pengusaha emping tike di Desa Jumbleng telah mampu memanfaatkan peluang yang ada untuk menghindari ancaman.

Tabel 6. Matriks EFE (Ekstrenal Factor Evaluation)

\begin{tabular}{|c|c|c|c|c|}
\hline Peluang $(\mathrm{O})$ & $\begin{array}{l}\text { Bobot } \\
\text { (B) }\end{array}$ & $\begin{array}{l}\text { Rating } \\
\text { (R) }\end{array}$ & $\begin{array}{l}\text { Skor } \\
(\mathrm{BxR})\end{array}$ & Prioritas \\
\hline 1. Dukungan dari pemerintah desa & & & & \\
\hline Setempat & 0.124 & 3 & 0,372 & 4 \\
\hline $\begin{array}{l}\text { 2. Memanfaatkan teknologi dan } \\
\text { informasi untuk memperluas areal promosi dan } \\
\text { menembus pasar }\end{array}$ & 0.133 & 3 & 0,399 & 4 \\
\hline $\begin{array}{l}\text { 3. Permintaan meningkat sangat pesat } \\
\text { pada saat hari-hari besar keagamaan }\end{array}$ & 0.124 & 3 & 0,372 & 3 \\
\hline 4. Peluang Pasar Masih Terbuka & 0.124 & 3 & 0,372 & 4 \\
\hline Jumlah & & 12 & 1,515 & \\
\hline Ancaman $(\mathrm{T})$ & 1 & & & \\
\hline 5. Duplikasi produk oleh usaha lain & 0.133 & 3 & 0,399 & 4 \\
\hline \multicolumn{5}{|l|}{$\begin{array}{l}\text { 6. Ketidaktersediaan bahan baku karena } \\
\text { perubahan musim yang }\end{array}$} \\
\hline Signifikan & 0.124 & 2 & 0,248 & 3 \\
\hline 7. Daya beli pelanggan menurun & 0.124 & 3 & 0,372 & 3 \\
\hline 8. Fluktuasi harga bahan baku & 0.115 & 2 & 0,230 & 3 \\
\hline Jumah & & 10 & 1,249 & \\
\hline Jumlah Total & & 22 & 2,764 & \\
\hline
\end{tabular}


Analisis Matriks Internal-Eksternal (IE)

Total Rata-Rata Tertimbang IFE

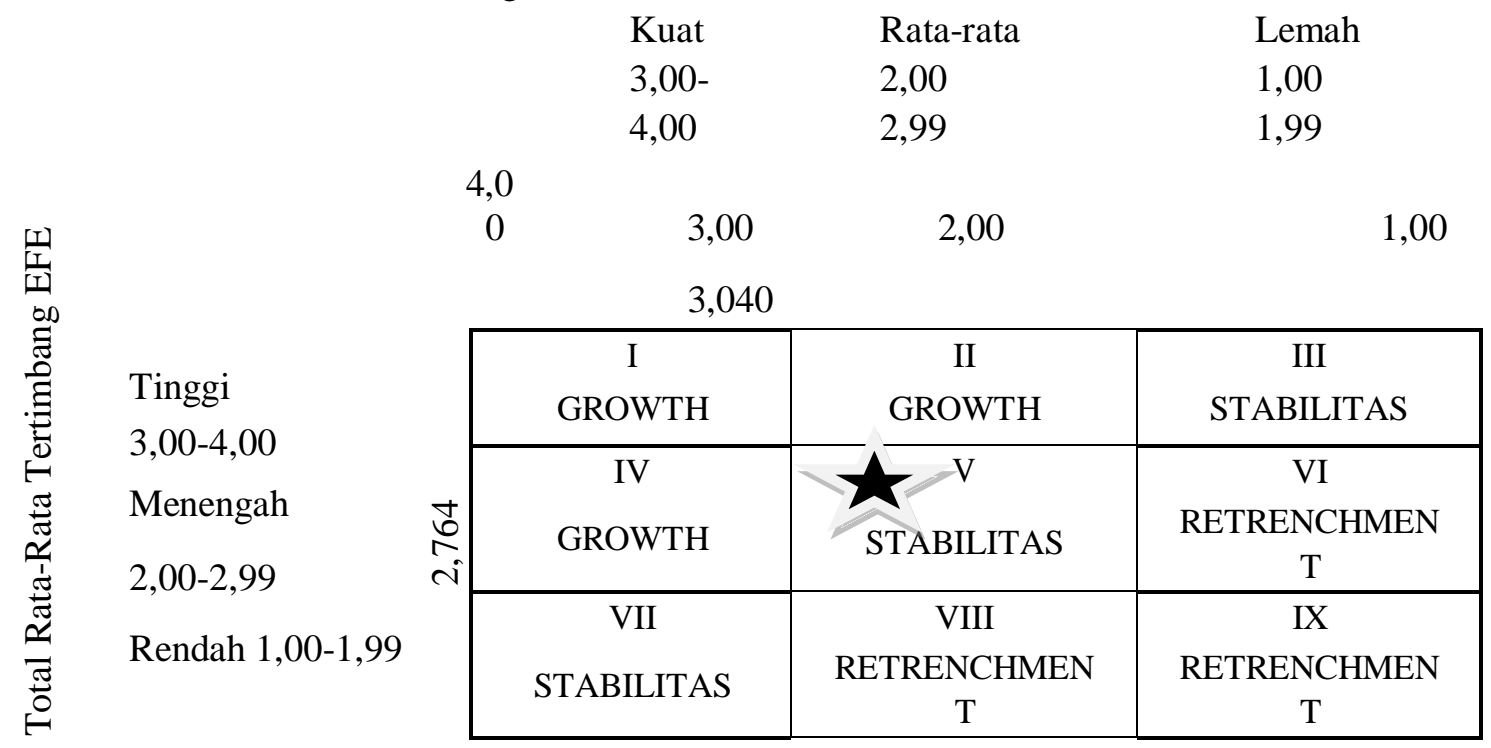

Sumber : David, 2006

Gambar 1. Matriks IE Pada matriks I-E ditunjukan bahwa posisi usaha emping tike di Desa Jumbleng Kecamatan Losarang Kabupaten Indramayu berada pada kuadran V yang artinya pertahankan atau pelihara.

\section{Matriks QSPM (Qualitatif Strategic Planning Matriks)}

Tabel 17. Strategi Yang Tepat Hasil Analisis Matriks QSPM

\begin{tabular}{lcc}
\hline & STRATEGI & TAS \\
\hline ST 1 & $\begin{array}{c}\text { Memanfaatkan teknologi dan informasi untuk meningkatkan } \\
\text { peminat dan memperluas areal promosi usaha emping tike } \\
\text { Memanfaatkan dukungan pemerintah untuk mempromosikan } \\
\text { emping tike agar emping tike dapat menembus pasar dan } \\
\text { banyak diminati oleh masyarakat. }\end{array}$ & 6,435 \\
ST 3 & 5,787 \\
& $\begin{array}{c}\text { Manfaatkan teknologi untuk mempermudah dalam proses } \\
\text { pembuatan dan pengemasan emping tike. }\end{array}$ & 5,467
\end{tabular}

Berdasarkan tabel tersebut jumlah TAS yang memiliki jumlah tertinggi yaitu ST 1 Memanfaatkan teknologi dan informasi untuk meningkatkan peminat dan memperluas areal promosi usaha emping tike. Merupakan strategi yang paling baik bagi usaha emping tike di Desa Jumbleng Kecamatan Losarang Kabupaten Indramayu dengan jumlah nilai sebanyak 6,435. 


\section{SIMPULAN DAN SARAN}

\section{Simpulan}

Berdasarkan hasil analisis yang telah dilakukan pada penelitian usaha emping tike di Desa Jumbleng Kecamatan Losarang Kabupaten Indramayu ini, maka diperoleh kesimpulan sebagai berikut

1. Berdasarkan hasil analisis, maka terdapat beberapa kekuatan dalam pengembangan usaha emping tike, antara lain. Tingginya kemauan dan keuletan pemilik dalam mengelola usaha, produk banyak diminati, memanfaatkan warga sekitar sebagai tenaga kerja, produk berkualitas dan memiliki izin. serta kelemahan yang perlu diperhatikan kurang adanya promosi, usaha tradisional, bahan baku relatif sulit, pembukuan masih sederhana. Sedangkan faktor peluang usaha emping tike antara lain Dukungan dari pemerintah setempat, adanya teknologi dan informasi untuk memperluas promosi dan pasar, permintaan tinggi pada saat hari- hari besar keagamaan, peluang pasar masih terbuka, sedangkan faktor ancaman antara lain duplikasi produk oleh usaha lain, ketidaktersediaan bahan baku sepanjang tahun, penurunan daya beli konsumen, dan fluktuasi harga bahan baku.

2 Berdasarkan matriks SWOT yang dilanjutan dengan matriks QSPM maka diperoleh prioritas strategi utama yang dapat diterapkan pada usaha emping tike di Desa Jumbleng Kecamatan Losarang Kabupaten Indramayu, yaitu memanfaatkan teknologi dan informasi untuk meningkatkan peminat dan memperluas areal promosi usaha emping tike.

\section{Saran}

Berdasarkan hasil penelitian dan pembahasan faktor internal dan ekternal yang dapat dijadikan strategi pengembangan usaha pada emping tike di Desa Jumbleng Kecamatan Losarang Kabupaten Indramayu, maka ada beberapa saran yang diajukan yaitu sebagai berikut:

1. Pengusaha emping tike di Desa Jumbleng Kecamatan Losarang Kabupaten Indramayu sebaiknya melakukan promosi dengan memanfaatkan media sosial ataupun mengikuti pameran kuliner yang mungkin diadakan oleh pemerintah daerah setempat.

2. Adanya bantuan pasokan bahan baku dari pemerintah desa setempat.

3. Desa menyediakan koperasi desa untuk membantu penjualan emping tike tersebut.

4. Pengusaha emping tike harus memiliki banyak saluran produsen yang dapat menyediakan bahan baku agar produksi tetap berjalan.

5. Memanfaatkan kredit yang ditawarkan oleh pihak lembaga keuangan untuk mengembangkan usahanya agar menjadi maju.

\section{Ucapan Terimakasih}

Ucapan Terimaksih saya ucapkan kepada Fakultas Pertanian dan LPPM UNWIR yang telah membantu dalam penelitian ini sehingga penelitian dapat dijalankan.

\section{DAFTAR PUSTAKA}

Aji Bayu P, 2012. Strategi Pengembangan Agroindustri Keripik Pisang di Kecamatan Tawangmangu Kabupaten Karanganyar. Surakarta.

Anggraeni Indah A. 2016. Strategi Pengembangan Usaha Industri Terasi (Pada Kasus Pabrik Terasi Merk Udang Kembar di Desa Tambak KecamatanIndramayu Kabupaten Indramayu tahun 2016). Indramayu. 
Badan Pusat Statistik Indramayu. 2016. Indramayu dalam angka 2016. Indramayu : Badan Pusat Statistik.

Brown dan Petrello. 1976. Introduction to Bussines, An Intergartion Approach Beverly Tulls: Glen Coe Press

Chooi, O.H, 2003. Sayuran dan Khasiat Makanan dan Obatan. Utusan Publication and Distributors Sdn. Kuala Lumpur.

David, F.R. 2004. “Manajemen Strategis: Konsep. Edisi ketujuh”. PT. Prenhallindo, Jakarta.

David, F.R. 2006. "Strategic Management". Concepts and Cases, $10^{\text {th }}$ Ed. Francis Marion university Florence, South Carolina.

Dinas Koperasi, UKM, Perindustrian dan Perdagangan Kabupaten Indramayu 2014. Daftar Pemilik Usaha Industri Keripik Tike Di Desa Jumbleng pada Tahun 2014.

Dinas Koperasi, UKM, Perindustrian dan Perdagangan Kabupaten Indramayu 2017. Daftar Sentra Industri Kecil dan Menengah pada Tahun 2017.

Dirgantoro $\quad$ C. 2004. Manajemen Stratejik. Jakarta : Gramedia.

Downey, W. D. Dan Steven P. Erickson, 1987. Manajemen Agribisnis. Erlangga, Jakarta.

Glueck dan Jauch, 1989. Manajemen Strategi dan Kebijakan Perusahaan. Jakarta, Erlangga.

Hariadi. 2005. Manajemen Strategis. Yogyakarta.

Hariyadi P. 2011. Riset dan Tenologi Pendukung peningkatan Kedaulatan Rakyat. Jurnal Hasibuan, Nurimansyah. 1993. Ekonomi Industri Persaingan, Monopoli dan Regulasi. Jakarta: LP3ES.

Heriyadi, Dedi, et al. 1993. Tahap perkembangan Usaha Kecil Dinamika dan Potensi Pertumbuhan AKATIGA. Bandung

Jauch Lawrence R. \& Glueck William F., (1989), Manajemen Dan Strategis Kebijakan Perusahaan. Jakarta : Erlangga.

Kinner, TC dan JR Taylor. 1991. Marketing Research: $\quad$ an Applied Approach. Mc GrawHill. New York.

Nazir.1988. Metode Penelitian. Jakarta : Ghalia Indonesia.

Oase, 2017. Budaya Indonesia Elemen Budaya Makanan atau Minuman Provinsi Jawa Barat Asal Daerah Indtamayu. https://budaya- indonesia.org/Keripik-Tike [dikutip 10 Oktober 2018]

Pasambuna M, 2003. Kajian Perencanaan dan Pengembangan Agroindustri Perikanan Rakyat di Kabupaten Bolaan Mongondow,Provinsi Sulawesi Utara [Tesis]. Bogor : Program Pasca Sarjana, Institut Pertanian Bogor.

Philip Kotler, 2002. Manajemen Pemasaran, Edisi Millenium, Jilid 2, PT. Prenhallindo, Jakarta. 
Pratomo TS, Soejoedono AR. 2002. Ekonomi Skala Kecil/Menengah dan Koperasi. Ghalila Indonesia: Jakarta.

Profil Desa Jumbleng Tahun 2014.

Purwanto I. 2008. Manajemen Strategi. Bandung : CV. Yrama Widya.

Rangkuti. 2009. Analisis SWOT Teknik membedah kasus bisnis.Gramedia. Jakarta.

Hakim S.S, 2018. Menganyam Purun Untuk Kelestarian Gambut.

Saragih B. 2010. Suara Dari Bogor : Membangun Opini Sistem Agribisnis. Bogo

PT. Penerbit IPB Press dan Food and Agribisnis Center.

Siagian, Sondang P. 2011. Manajemen Strategik. Jakarta : PT Bumi Aksara.

Soeharjo, 1991. Konsep dan Ruang Lingkup Agroindustri dalam Kumpulan Makalah Seminar Agribisnis. Buku I. Jurusan Ilmu-ilmu Sosial Ekonomi Pertanian. Fakultas Pertanian IPB. Bogor.

Soekartawi, 2001. Pengantar Agroindustri. PT. Raja Grafindo Persada. Jakarta.

Sonjanawati, dkk, 2018. Keragaan Usaha dan Nilai Tambah Pada Agroindustri Keripik Tike (Studi Kasus di Desa Jumbleng Kecamatan Losarang Indramayu).Prodi Agribisnis Fakultas Pertanian. Universitas Padjajaran. Bandung Surat keputusan Mentri Perindustrian no. 135/M/SK/8/1997.

Tambunan, 2002. Usaha Kecil dan Menengah di Indonesia Beberapa Isu Penting. Jakarta: Penebar Swadaya.Undang-undang Nomor 20 Tahun 2008. Tentang UMKM.

Wardiono, 2007. Eleochardis dulcis Burm. F.) Trinius ex

Henschell. http://www.Kehati.or.id/prohat i/browser.php/docsid=478. [23 april 2008].

Wibisono. 2006. Manajemen Kinerja: Konsep Desain dan Teknik Meningkatkan Daya Saing Perusahaan, Jakarta : Erlangga. 